\title{
UNUSUAL MECHANISM OF THE METHANOLYSIS OF 1-CYANOFORMAMIDINES
}

\author{
Cristina FLOREA, Anca HÎRTOPEANU, Cristina STAVARACHE and Horia PETRIDE* \\ “Costin D. Nenitzescu” Center of Organic Chemistry, Spl. Independenței 202-B, RO-060023 Bucharest, Roumania
}

Base-catalyzed methanolysis of $N$-benzyl- $N$-methyl-1cyanoformamidine (7) gives methyl $N$-benzyl- $N$-methylcarbamimidate (8) as final reaction product. Transient formation of $N$-benzyl- $N$-methylcyanamide (9) was observed also. Kinetic data showed two competitive routes in action: (i) $\mathbf{7} \rightarrow \mathbf{9} \rightarrow \mathbf{8}$ and (ii) directly $\mathbf{7} \rightarrow \mathbf{8}$. The proposed reaction mechanism is based on the dual behaviour of 7: (i) as an acid and (ii) as an electrophile.

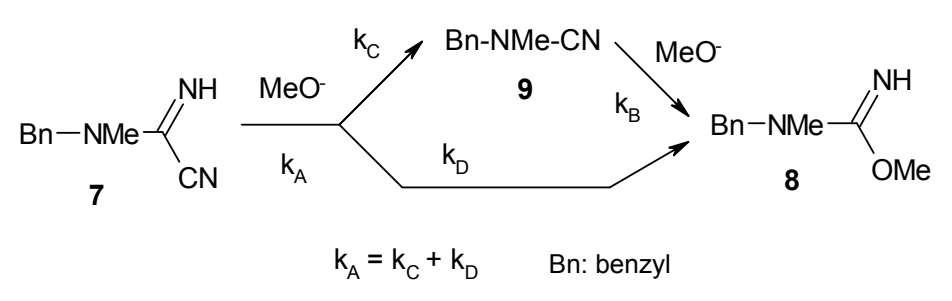

\section{INTRODUCTION}

Amidines (1, Scheme 1) and especially formamidines $(1, \mathrm{R}=\mathrm{H})$ have been used extensively as pharmacological agents, ${ }^{1 \mathrm{a}}$ pesticides,${ }^{1 \mathrm{~b}}$ electrophiles, ${ }^{1 \mathrm{c}}$ in asymmetric preparations, ${ }^{1 \mathrm{~d}}$ as well as protective groups for primary amino function, for example in nucleosides. ${ }^{\text {le }}$ In this last case, the deprotection is achieved usually by hydrolysis and this might explain why chemists have been so attracted by this reaction, ${ }^{1,2-4}$ including theoretically. ${ }^{5 a-d}$

Generally, the hydrolysis studies agree with the mechanism presented in Scheme 1. The transient tetrahedral intermediate, the hemiorthoamide 2, can be cleaved in two different ways, depending on the single bond which is broken: $\mathrm{N}^{(1)}-\mathrm{C}$ or $\mathrm{C}-\mathrm{N}^{(2)}$ (path $a$ or $b$, respectively). Different amide+amine mixtures result through these pathways, but the prevailing route is that giving the more basic amine. ${ }^{1 e, 4 d}$ Hydrolysis rate is subjected to general acid-base catalysis. ${ }^{4 b}$ Usually, the base-catalyzed reactions are more rapid than those in acid media. ${ }^{4 \mathrm{~b}, 5 \mathrm{a}}$

It is known that the $\mathrm{C}=\mathrm{N}$ group in amidines is hydrolyzed under milder conditions than the $\mathrm{C} \equiv \mathrm{N}$ in nitriles or the $\mathrm{C}=\mathrm{O}$ group in amides or esters. ${ }^{6 \mathrm{a}}$
However, when additional organic functions like $\mathrm{C}=\mathrm{O}$ or $\mathrm{C} \equiv \mathrm{N}$ are present in $\mathbf{1}$, close to the amidine moiety, the expected trend in reactivity is no more followed. Two examples of alcoholysis of carbonyl-containing formamidines are offered in Scheme 2: the carbonylic carbon atom and not the amidine central carbon is attacked in $\mathbf{3}$ (preferentially) ${ }^{6 \mathrm{~b}}$ and $\mathbf{4}$ (solely). ${ }^{6 \mathrm{c}}$

Another example is the hydrolysis of 1-cyanoformamidine 5 (Scheme 3) ${ }^{\text {7a-b }}$ The carbamylformamidine $\mathbf{6}$ was the first reaction intermediate formed, regardless of the acidic (i) or basic (ii) reaction medium. This experimental reactivity order $(\mathrm{C} \equiv \mathrm{N}>$ $\mathrm{C}=\mathrm{N}$ ) in $\mathbf{5}$ was just the opposite of that expected.

During our studies on the $\mathrm{RuO}_{4}$-mediated oxidation of secondary aliphatic amines ${ }^{8}$ we found various reaction products, but in particular conditions 1-cyanoformamidines prevailed. For instance, the oxidation of benzylmethylamine in the presence of $\mathrm{NaCN}$ gave $N$-benzyl- $N$-methyl-1-cyanoformamidine (7) as main compound, accompanied by some hydrolysis products. Preliminary experiments ${ }^{8}$ on the hydrolysis of 7 seemed to indicate the implication of both $\mathrm{C} \equiv \mathrm{N}$ and $\mathrm{C}=\mathrm{N}$ groups, similarly to Schemes 1 and 3. 


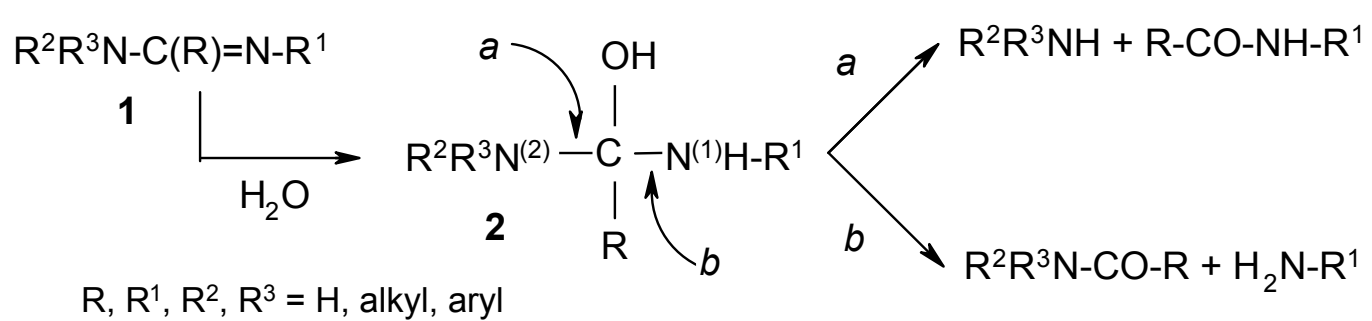

Scheme 1

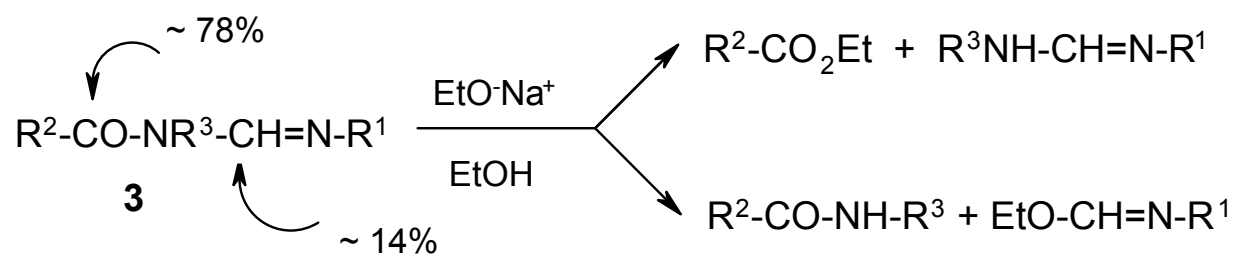

$\mathrm{R}^{1}=\mathrm{p}-\mathrm{O}_{2} \mathrm{~N}-\mathrm{C}_{6} \mathrm{H}_{4^{-}}, \mathrm{R}^{2}=\mathrm{p}-\mathrm{Cl}-\mathrm{C}_{6} \mathrm{H}_{4^{-}}, \mathrm{R}^{3}=\mathrm{p}-\mathrm{Me}-\mathrm{C}_{6} \mathrm{H}_{4}-\mathrm{CH}_{2}-$

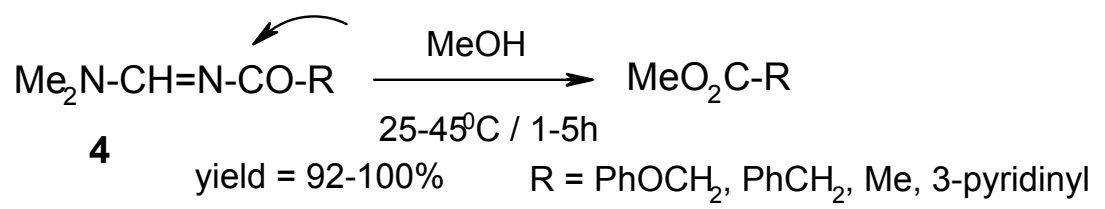

Scheme 2

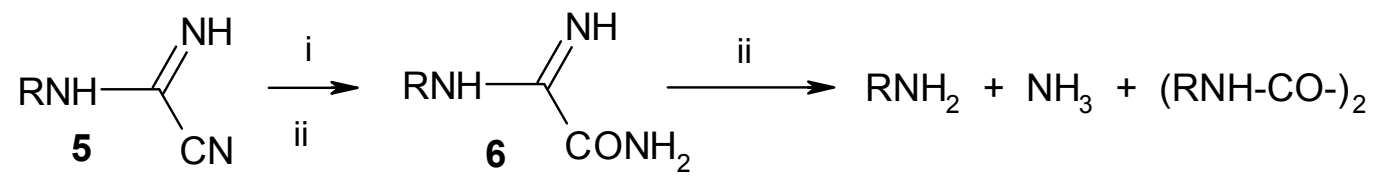

(i) aq. $\mathrm{HCl}$, r.t.; (ii) "warm" $20 \%$ aq. $\mathrm{NaOH}$; R: pyridinyl

Scheme 3

Contrarily to hydrolysis, the information about the amidine alcoholysis is very poor. Some examples with carbonyl-containing formamidines were already shown in Scheme 2, but analogous reactions with 1-cyanoformamidines are lacking. We present in this paper the unexpected results obtained for the methanolysis of 7 .

\section{RESULTS}

The final methanolysis product of 7 was methyl carbamimidate $\mathbf{8}$, but small amounts of cyanamide 9 were observed transiently during the reaction (Scheme 4). At any time, the mass law of equation 1 was followed. Throughout this paper, the concentration of a particular compound (e.g. 7) is indicated by its number or formula in right brackets (i.e., [7]), eventually with a zero subscript if the initial concentration is intended.

$$
[7]_{0}=[7]+[8]+[9]
$$

A typical course of reaction is shown in Figure 1, where the variation of concentration of a particular compound (relative to [7] $]_{0}$ ) was depicted against time. Compound 9 is a true intermediate since it appears at the beginning and is transformed entirely in $\mathbf{8}$ towards the end of the reaction. In analogous reaction conditions, cyanamide 9 behaved as an ordinary nitrile by giving the same 8. As presented below, the rates are first order in $\mathrm{MeONa}$ and first order in the starting material ( 7 or 9). However, by choosing $\left[\mathrm{MeO}^{-}\right]_{0} \gg[7]_{0}$ (as in Fig. 1), all methanolyses can be treated as pseudofirst order reactions, because $\left[\mathrm{MeO}^{-}\right] \approx\left[\mathrm{MeO}^{-}\right]_{0}$ during the reaction. The second order rate constants were determined by varying the ratio $\left[\mathrm{MeO}^{-}\right]_{0} /[7]_{0}$, within the pseudo-first order approximation. 


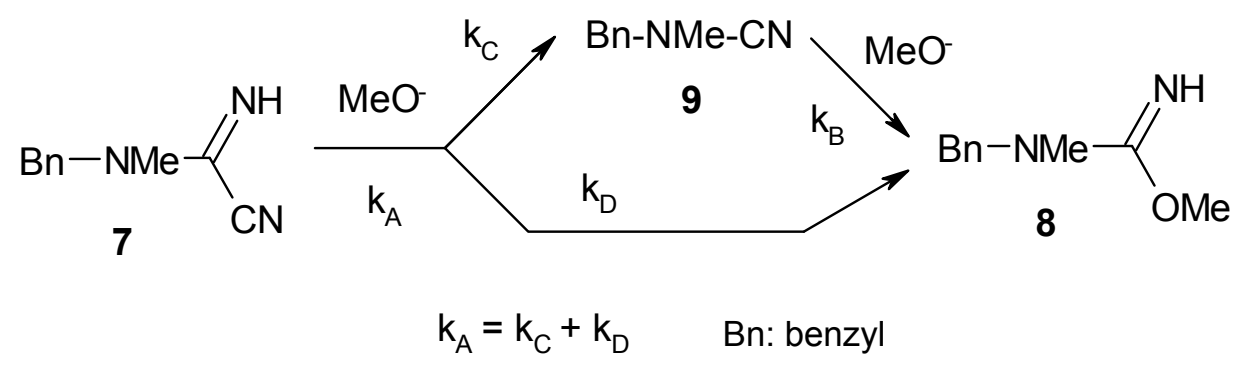

Scheme 4

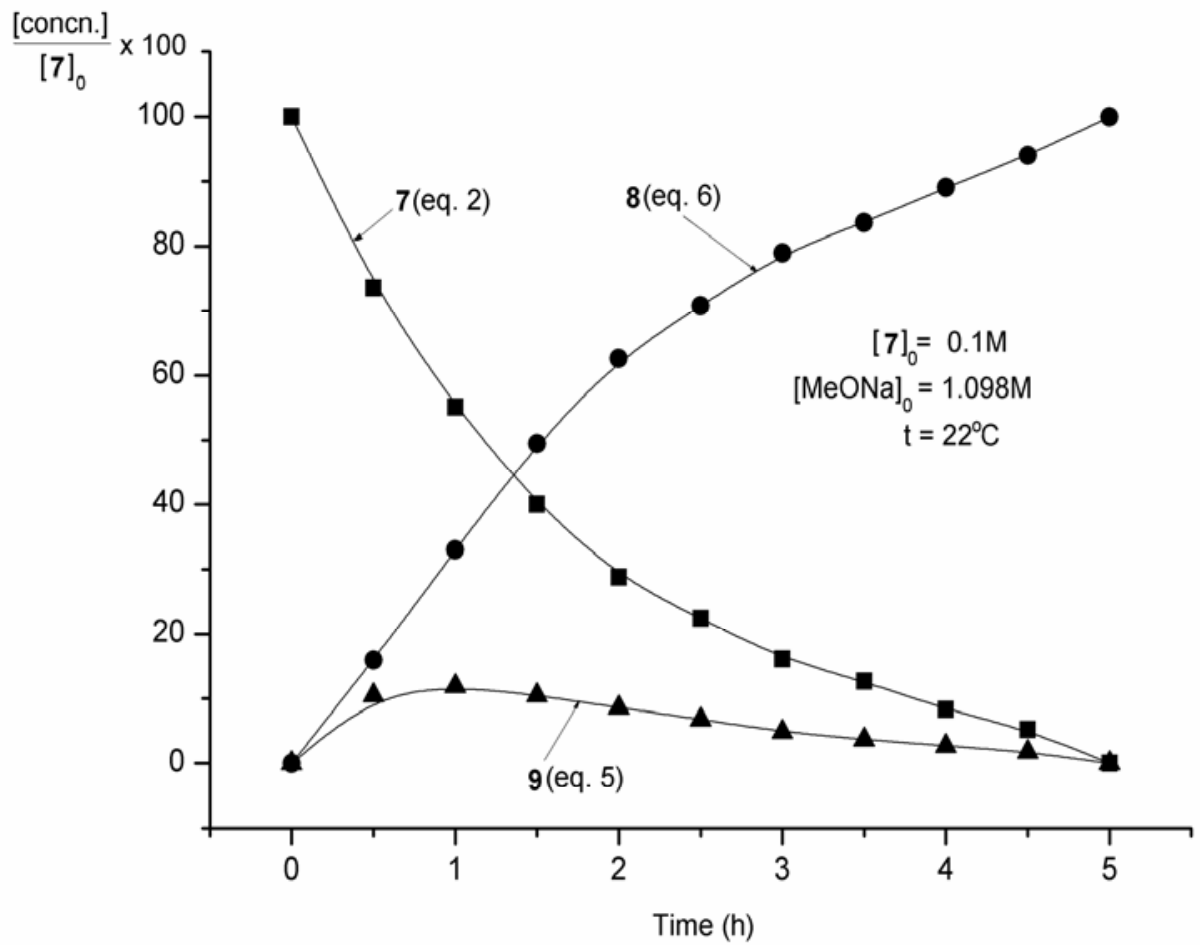

Fig. 1 - Methanolysis of formamidine 7.

Variation of [7] with time is described by equation 2, where the rate constant $\mathrm{k}_{\mathrm{A}}$ is explicitated below.

From separate experiments, we obtained the equation 3 for the transformation of 9 to $\mathbf{8}$. The corresponding rate constant $\mathrm{k}_{\mathrm{B}}$ is about 2.8 times greater than $\mathrm{k}_{\mathrm{A}}$.

Maintaining the pseudo-first order conditions for the consecutive "unimolecular" reactions $7 \rightarrow$ $\mathbf{9} \rightarrow \mathbf{8}$ and knowing $\mathrm{k}_{\mathrm{A}}$ and $\mathrm{k}_{\mathrm{B}}$, the variation of [9] with time should agree to equation $4 .{ }^{10}$
However, to our surprise, the calculated values of [9] were constantly greater than the experimental ones. In other words, it seemed that only some part of $\mathbf{7}$ followed the sequence $\mathbf{7} \rightarrow \mathbf{9}$ $\rightarrow \mathbf{8}$. The remaining part of $\mathbf{7}$ was transformed into 8 by another route, without passing through 9 . This is depicted in Scheme 4, where $\mathrm{k}_{\mathrm{A}}$ in equation 2 is now the sum of two new rate constants $\mathrm{k}_{\mathrm{C}}$ and $\mathrm{k}_{\mathrm{D}}$.

In this case, the equation 4 is replaced by equation 5 , where $\mathrm{k}_{\mathrm{C}}$ is unknown.

$$
\begin{gathered}
{[7] /[7]_{0}=\exp \left(-\mathrm{k}_{\mathrm{A}} \mathrm{t}\right) \text {, where } \mathrm{k}_{\mathrm{A}}\left(22^{\circ} \mathrm{C}\right)=1.57 \times 10^{-4} \times\left[\mathrm{MeO}_{0}\right]\left(\mathrm{s}^{-1}\right)} \\
{[9] /[9]_{0}=\exp \left(-\mathrm{k}_{\mathrm{B}} \mathrm{t}\right) \text {, where } \mathrm{k}_{\mathrm{B}}\left(22^{\circ} \mathrm{C}\right)=4.46 \times 10^{-4} \times[\mathrm{MeO}]_{0}\left(\mathrm{~s}^{-1}\right)} \\
{[9] /[7]_{0}=\frac{\mathrm{k}_{\mathrm{A}}}{\mathrm{k}_{\mathrm{B}}-\mathrm{k}_{\mathrm{A}}} \times\left\{\exp \left(-\mathrm{k}_{\mathrm{A}} \mathrm{t}\right)-\exp \left(-\mathrm{k}_{\mathrm{B}} \mathrm{t}\right)\right\}}
\end{gathered}
$$




$$
[9] /[7]_{0}=\frac{k_{C}}{k_{B}-k_{A}} \times\left\{\exp \left(-k_{A} t\right)-\exp \left(-k_{B} t\right)\right\},
$$

where $\mathrm{k}_{\mathrm{A}}=\mathrm{k}_{\mathrm{C}}+\mathrm{k}_{\mathrm{D}}$

$$
\begin{array}{ll}
\mathrm{k}_{\mathrm{C}}\left(22^{\circ} \mathrm{C}\right)=0.61 \mathrm{k}_{\mathrm{A}}=0.96 \times 10^{-4} \times\left[\mathrm{MeO}^{-}\right]_{0} & \left(\mathrm{~s}^{-1}\right) \\
\mathrm{k}_{\mathrm{D}}\left(22^{\circ} \mathrm{C}\right)=0.39 \mathrm{k}_{\mathrm{A}}=0.61 \times 10^{-4} \times\left[\mathrm{MeO}^{-}\right]_{0} & \left(\mathrm{~s}^{-1}\right)
\end{array}
$$

A convenient value for $\mathrm{k}_{\mathrm{C}}$ was found by employing in equation 5 values $\mathrm{k}_{\mathrm{C}}<\mathrm{k}_{\mathrm{A}}$ and comparing the calculated [9] with the experimental values. The best fit was obtained with $\mathrm{k}_{\mathrm{C}}=0.61 \mathrm{k}_{\mathrm{A}}$, as indicated above. It results that amidine 7 reacts with methoxide anion by two concurrent ways: (i) through the intermediacy of cyanamide 9 and (ii) directly to the final product 8 . The first route occurs about $\mathrm{k}_{\mathrm{C}} / \mathrm{k}_{\mathrm{D}} \approx 1.6$ times faster than the second.

The curve describing the variation of [9] with time (Fig. 1) has a maximum. It occurs when $\mathrm{d}[\mathbf{9}] / \mathrm{dt}=0$, which means at $\mathrm{t}_{\max }=\left(1 /\left(\mathrm{k}_{\mathrm{B}}-\mathrm{k}_{\mathrm{A}}\right)\right) \mathrm{x}$ $\ln \left(\mathrm{k}_{\mathrm{B}} / \mathrm{k}_{\mathrm{A}}\right)=55 \mathrm{~min}$. The variation of [8] with time in Figure 1 was calculated with the equation 6 (derived from eq. 1), where $[7] /[7]_{0}$ and $[9] /[7]_{0}$ come from equations 2 and 5, respectively.

$$
[8] /[7]_{0}=1-[7] /[7]_{0}-[9] /[7]_{0} \quad \text { (eq. 6) }
$$

Same kinetic results were obtained working in $\mathrm{CD}_{3} \mathrm{ONa} / \mathrm{CD}_{3} \mathrm{OD}$ medium. The final product was now Bn-NMe-C(=ND)-OCD 3 (8a), whatever the starting material ( 7 or 9 ). When the genuine final reaction mixture was diluted with water in order to isolate 8a (see Experimental), the obtained product was instead $\mathrm{Bn}-\mathrm{NMe}-\mathrm{C}(=\mathrm{NH})-\mathrm{OCD}_{3} \quad(\mathbf{8 b})$. This means that the hydrogen atom of the $\mathrm{N}-\mathrm{H}$ group in 7 and $\mathbf{8}$ is interchangeable with deuterium in basic media.

\section{DISCUSSION}

Considering all aforementioned experimental information, we imagined a mechanism, shown in Scheme 5, aiming to explain the two routes. The steps 1-4 describe the first route $(\mathbf{7} \rightarrow \mathbf{9} \rightarrow \mathbf{8})$ and the last two steps (5 and 6) are connected to the second route $(\mathbf{7} \rightarrow \mathbf{8})$. Three new structures (10-12) are introduced in Scheme 5. They can be considered either as intermediates or as transition states, but the following kinetic treatment is the same.

Structure 10, generated in step 1, is the source of cyanamide 9 (step 2) through a convenient expulsion of cyanide anion, a good leaving group.
The subsequent transformations $\mathbf{9} \rightarrow(\mathbf{1 1}) \rightarrow \mathbf{8}$ (steps 3 and 4) describe the generally accepted mechanism for the base-catalyzed alcoholysis of a nitrile. ${ }^{9}$ Species like $\mathbf{1 0}$ or $\mathbf{1 1}$ are involved in the deuterium/hydrogen exchange reaction proved for $\mathbf{8 a} \rightarrow \mathbf{8 b}$, as mentioned before.

The direct transformation of $\mathbf{7}$ into $\mathbf{8}$ (steps 5 and 6) implies the transient formation of $\mathbf{1 2}$. Similarly to step 2, the driving force for the generation of $\mathbf{8}$ from 12 (step 6) is the electronically assisted elimination of $\mathrm{CN}^{-}$. Steps 5 and 6 are similar to those of Scheme 1 , but with one notable difference. Contrarily to 2 , the $\mathrm{C}-\mathrm{CN}$ bond instead of $\mathrm{C}-\mathrm{N}^{(1)} / \mathrm{C}-\mathrm{N}^{(2)}$ is broken now in the tetrahedral intermediate 10. Clearly, the cyanide anion is a better leaving group than an aminic moiety.

According to steps 1-6 of Scheme 5, the variation of [7] with time is described by the differential equation 7. Concentrations of the two intermediates 10 and 12, present in equation 7 , can be found by assuming the steady state approximation: their concentrations are small and $\mathrm{d}[\mathbf{1 0}] / \mathrm{dt}$ (eq. 8) and $\mathrm{d}[\mathbf{1 2}] / \mathrm{dt}$ (eq. 9) can be safely considered zero. In this case, [10] and [12] are given by the corresponding equations 10 and 11 , respectively. With these values, the equation 7 becomes the equation 12, for which the analytical solution is identical to the experimental equation 2, if $\mathrm{k}_{1}=\mathrm{k}_{\mathrm{C}}, \mathrm{k}_{5}=\mathrm{k}_{\mathrm{D}}, \mathrm{k}_{\mathrm{A}}=\mathrm{k}_{\mathrm{C}}+\mathrm{k}_{\mathrm{D}}$, and $\left[\mathrm{MeO}^{-}\right]=\left[\mathrm{MeO}^{-}\right]_{0}$.

Scheme 5 suggests the differential equation 13 for the variation of [9] with time. Considering $\mathrm{d}[\mathbf{1 1}] / \mathrm{dt}=0$ (eq. 14), the resulted value of [11] (eq. 15) can be introduced into equation 13, together with the known value of $[\mathbf{1 0}]$ (eq. 10). The newly resulted differential equation 16 can be solved by the well known integrating factor method. ${ }^{10,11}$ Its integrated solution is identical to the experimental equation 5 if $\mathrm{k}_{1}=\mathrm{k}_{\mathrm{C}}$, $\mathrm{k}_{3}=\mathrm{k}_{\mathrm{B}}$, and $\left[\mathrm{MeO}^{-}\right]=\left[\mathrm{MeO}^{-}\right]_{0}$.

It results that the mechanism proposed in Scheme 5 leads to kinetic expressions for [7], [8], and [9] in accord with the experimentally observed equations. We must remember that all equations 2-5 are valid only in pseudo-first order conditions. 
(step 1)

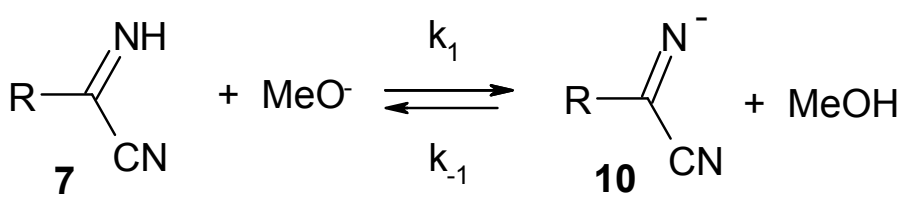

(step 2)

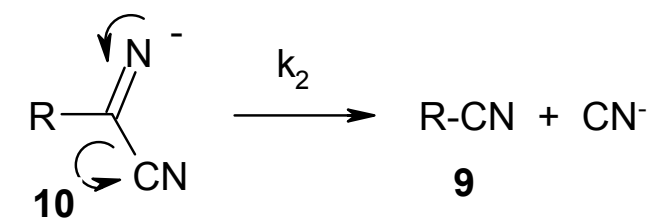

$\mathrm{R}: \mathrm{Bn}-\mathrm{NMe}-$

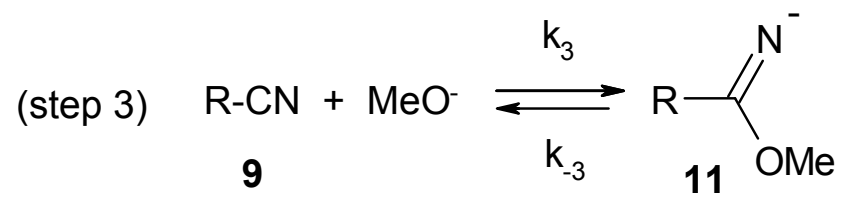

(step 4)

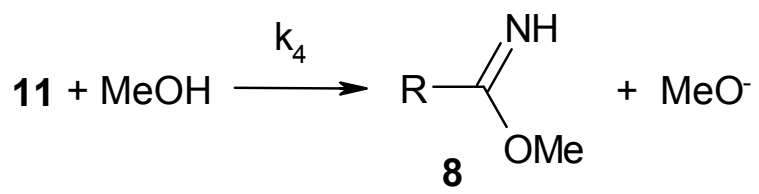

(step 5)

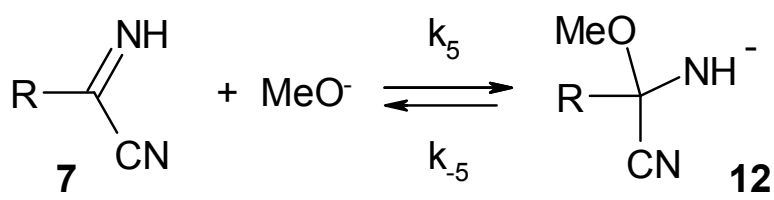

(step 6)

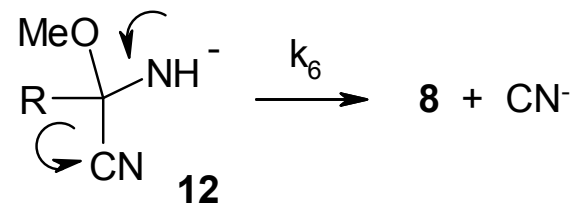

Scheme 5

$$
\begin{aligned}
& \mathrm{d}[7] / \mathrm{dt}=-\mathrm{k}_{1}[\mathrm{MeO}][7]+\mathrm{k}_{-1}[\mathrm{MeOH}][10]-\mathrm{k}_{5}[\mathrm{MeO}][7]+\mathrm{k}_{-5}[12] \\
& \mathrm{d}[\mathbf{1 0}] / \mathrm{dt}=\mathrm{k}_{1}[\mathrm{MeO}][\mathbf{7}]-\mathrm{k}_{-1}[\mathrm{MeOH}][10]-\mathrm{k}_{2}[10]=0 \\
& \mathrm{~d}[\mathbf{1 2}] / \mathrm{dt}=\mathrm{k}_{5}[\mathrm{MeO}][7]-\mathrm{k}_{-5}[12]-\mathrm{k}_{6}[12]=0 \\
& {[10]=\mathrm{k}_{1}\left[\mathrm{MeO}^{-}\right][7] /\left(\mathrm{k}_{-1}[\mathrm{MeOH}]+\mathrm{k}_{2}\right)} \\
& \text { [12] }=\mathrm{k}_{5}\left[\mathrm{MeO}^{-}\right][7] /\left(\mathrm{k}_{-5}+\mathrm{k}_{6}\right) \\
& \mathrm{d}[7] / \mathrm{dt}=-\left(\mathrm{k}_{1}\left[\mathrm{MeO}^{-}\right]+\mathrm{k}_{5}\left[\mathrm{MeO}^{-}\right]\right)[7], \quad \text { if } \mathrm{k}_{2}>>\mathrm{k}_{-1}[\mathrm{MeOH}] \text { and } \mathrm{k}_{6}>>\mathrm{k}_{-5} \\
& \mathrm{~d}[\mathbf{9}] / \mathrm{dt}=\mathrm{k}_{2}[10]-\mathrm{k}_{3}\left[\mathrm{MeO}^{-}[\mathbf{9}]+\mathrm{k}_{-3}[11]\right. \\
& \mathrm{d}[\mathbf{1 1}] / \mathrm{dt}=\mathrm{k}_{3}[\mathrm{MeO}][9]-\mathrm{k}_{-3}[11]-\mathrm{k}_{4}[\mathrm{MeOH}][11]=0 \\
& \text { [11] }=\mathrm{k}_{3}\left[\mathrm{MeO}^{-}\right][9] /\left(\mathrm{k}_{4}[\mathrm{MeOH}]+\mathrm{k}_{-3}\right) \\
& \mathrm{d}[\mathbf{9}] / \mathrm{dt}=\mathrm{k}_{1}\left[\mathrm{MeO}^{-}\right][7]-\mathrm{k}_{3}\left[\mathrm{MeO}^{-}\right][9], \quad \text { if } \mathrm{k}_{4}[\mathrm{MeOH}]>>\mathrm{k}_{-3}
\end{aligned}
$$




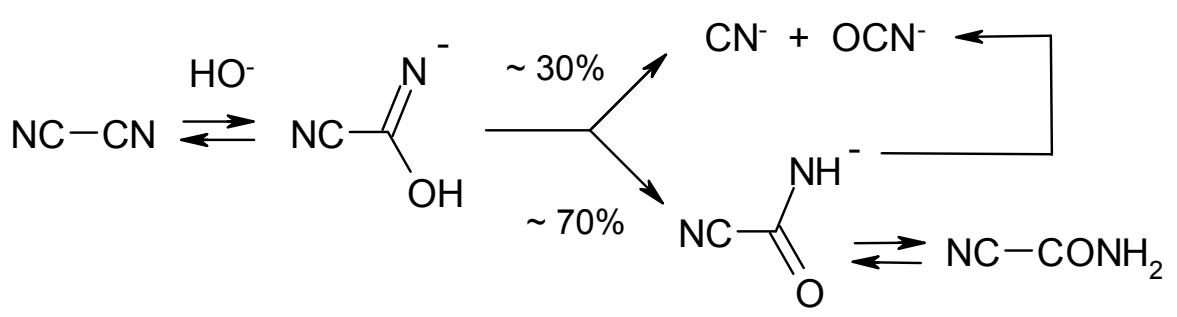

Scheme 6

The dual mechanism of Scheme 5 resembles in some way to the one proposed for the hydrolysis of cyanogen (Scheme 6). ${ }^{12}$ However, in this last case, the two routes start from the same intermediate, the cyanogen having no N-H bond as in 7 .

The mechanism depicted in Scheme 5 is different from those anticipated in Schemes 1-3. In our opinion, the unexpected behaviour of 1-cyanoformamidine 7 towards the methoxide anion is due mainly to the presence of the cyano substituent, a good leaving group in basic conditions. At the same time, it is interesting to see 7 acting with $\mathrm{MeO}^{-} / \mathrm{MeOH}$ either as an acid (step 1) or as an electrophile (step 5).

\section{EXPERIMENTAL}

\section{General}

Elemental analyses were performed with EAS32 Station Costech 2002. NMR spectra were acquired on a Varian ICON 300 apparatus, operating at $300 \mathrm{MHz}\left({ }^{1} \mathrm{H}\right)$ and $75 \mathrm{MHz}\left({ }^{13} \mathrm{C}\right)$. The corresponding chemical shifts ( $\delta$ scale) were referenced to internal TMS $\left(\delta_{\mathrm{H}}=0 \mathrm{ppm}\right)$ or $\mathrm{CDCl}_{3}\left(\delta_{\mathrm{C}}=77.16 \mathrm{ppm}\right)$. Interproton coupling constants $J$ were given in $\mathrm{Hz}$. Mass spectra were obtained with a GC 6890 Agilent Technologies gas chromatograph coupled with a MS 5975B mass spectrometer, using $70 \mathrm{eV}$ as ionization energy. Preparation and characterization of 7 and 9 were reported by us previously. ${ }^{8}$

\section{Methyl $N$-benzyl- $N$-methylcarbamimidate $(8)$}

To a methanolic solution of sodium methoxide [prepared from metallic $\mathrm{Na}(83 \mathrm{mg}, 3.6 \mathrm{at}-\mathrm{mg})$ in anhydrous methanol $(2.5 \mathrm{~mL})$ ] is added $9(110 \mathrm{mg}, 0.74 \mathrm{mmol})$ dissolved in methanol $(1 \mathrm{~mL})$ and the clear solution is magnetically stirred at room temperature for 6 hours. The solution is diluted with water $(10 \mathrm{~mL})$ and extracted with chloroform $(3 \times 5 \mathrm{~mL})$. The combined organic extracts are dried on anhydrous $\mathrm{Na}_{2} \mathrm{SO}_{4}$ and the solvent is removed to leave $\mathbf{8}$ as a colorless oil $(120 \mathrm{mg}$; yield 91\%). Elemental analysis. Theoretical (\%) for $\mathrm{C}_{10} \mathrm{H}_{14} \mathrm{~N}_{2} \mathrm{O}$ : $\mathrm{C}$ (67.39), $\mathrm{H}$ (7.92), $\mathrm{N}$ (15.72); found (\%):C (67.71), H (8.20), N (15.58). Further purification by column chromatography or distillation failed.

${ }^{1} \mathrm{H}-\mathrm{NMR}$ spectrum $\left(\mathrm{CDCl}_{3}, \delta, \mathrm{ppm}\right): 2.83\left(\mathrm{~s}, 3 \mathrm{H}, \mathrm{NCH}_{3}\right)$, $3.77\left(\mathrm{~s}, 3 \mathrm{H}, \mathrm{OCH}_{3}\right), 4.43$ (s, $\left.2 \mathrm{H}, \mathrm{Ph}-\mathrm{CH}_{2}\right), 7.19$ (dd, $J=7.2$ and $\left.1.4,2 \mathrm{H}, \mathrm{H}_{o}\right), 7.25\left(\mathrm{tt}, J=7.3\right.$ and $\left.1.4,1 \mathrm{H}, \mathrm{H}_{p}\right), 7.33(\mathrm{tt}$, $J=7.1$ and $1.4,2 \mathrm{H}, \mathrm{H}_{m}$ ).

${ }^{13} \mathrm{C}$-NMR spectrum $\left(\mathrm{CDCl}_{3}, \delta, \mathrm{ppm}\right): 35.3\left(\mathrm{NCH}_{3}\right), 53.0$ $\left(\mathrm{Ph}-\mathrm{CH}_{2}\right), 53.7\left(\mathrm{OCH}_{3}\right), 127.0\left(\mathrm{C}_{o}\right), 127.1\left(\mathrm{C}_{p}\right), 128.5\left(\mathrm{C}_{m}\right)$, $138.1\left(\mathrm{C}_{i}\right), 161.45(\mathrm{C}=\mathrm{N})$.
MS spectrum (m/z, \%): $178\left(\mathrm{M}^{+}, 46\right), 177$ (25), 163 (57), 121 (11), 120 (100), 106 (25), 91 (53).

Trideuteromethyl $N$-benzyl- $N$-methylcarbamimidate (8b)

It was obtained from 7 or 9 during the kinetic experiments in $\mathrm{CD}_{3} \mathrm{ONa} / \mathrm{CD}_{3} \mathrm{OD}$, followed by dilution with water (see below). Its NMR features are identical to those of $\mathbf{8}$, except the lack of $\mathrm{OCD}_{3}$ signal.

MS spectrum (m/z, \%): $181\left(\mathrm{M}^{+}, 39\right), 180$ (20), 166 (17), 164 (10), 163 (25), 121 (14), 120 (100), 106 (25), 91 (58), 77 (10), 65 (19), 61 (13), 44 (15), 42 (23).

\section{Kinetic measurements}

Method A (Fig. 1). A methanolic solution of $\mathrm{MeONa}$ [obtained from metallic sodium $(631.4 \mathrm{mg} ; 27.45$ at $-\mathrm{mg})$ and anhydrous methanol $(15 \mathrm{~mL})]$ was diluted with a solution of formamidine 7 (purity 99\%; $437 \mathrm{mg}, 2.5 \mathrm{mmol}$ ) and $p$-dimethoxybenzene (pDMB; $60 \mathrm{mg}, 0.435 \mathrm{mmol}$; internal standard) in anhydrous methanol (about $5 \mathrm{~mL}$ ). The whole mixture was diluted to a volume of $25 \mathrm{~mL}$ and then transferred into the reaction vessel immersed in a constant-temperature bath at $22^{\circ} \mathrm{C}$. The initial concentrations were $[7]_{0}=0.1 \mathrm{M},\left[\mathrm{MeO}^{-}\right]_{0}=$ $1.098 \mathrm{M}$ and $[\mathrm{pDMB}]=0.0174 \mathrm{M}$. Aliquots of $1.5 \mathrm{~mL}$ were withdrawn with a syringe, poured into cold water $(10 \mathrm{~mL})$, and extracted with dichlorometane $(3 \times 3 \mathrm{~mL})$. The combined organic extracts were dried $\left(\mathrm{Na}_{2} \mathrm{SO}_{4}\right)$ and the solvent was removed in vacuo. The residue was dissolved in $\mathrm{CDCl}_{3}$ and analyzed by NMR and GC-MS. The NMR integrals were measured against those of pDMB occuring at $6.81 \mathrm{ppm}(4 \mathrm{H})$ and $3.75 \mathrm{ppm}(6 \mathrm{H})$. Second-order rate constants were obtained by varying the ratio $[7]_{0} /\left[\mathrm{MeO}^{-}\right]_{0}$.

Method B. Alternatively, the reaction was monitored in $\mathrm{CD}_{3} \mathrm{ONa} / \mathrm{CD}_{3} \mathrm{OD}$ directly in the NMR tube, using correspondingly reduced masses and volumes. The new kinetic results were identical to those previously obtained. This means that cyanamide 9 was not an artefact of sample manipulation.

Analogous kinetic experiments were performed with cyanamide 9 and either $\mathrm{CH}_{3} \mathrm{ONa} / \mathrm{CH}_{3} \mathrm{OH} \quad(A)$ or $\mathrm{CD}_{3} \mathrm{ONa} / \mathrm{CD}_{3} \mathrm{OD}$ system $(B)$. In the last case, the final reaction product present in the NMR tube was Bn-NMe$\mathrm{C}(=\mathrm{ND})-\mathrm{OCD}_{3}(\mathbf{8 a})$. When treated as in method $A$ (with water and $\mathrm{CH}_{2} \mathrm{Cl}_{2}$ ), the isolated compound corresponded to $\mathrm{Bn}$ $\mathrm{NMe}-\mathrm{C}(=\mathrm{NH})-\mathrm{OCD}_{3}(\mathbf{8 b})$ (see above).

\section{CONCLUSIONS}

1-Cyanoformamidine 7 undergoes basic methanolysis to carbamimidate 8 by two routes: (i) through the intermediacy of cyanamide 9 and (ii) directly. All reactions show second order kinetics, 
first order in both $\mathrm{MeONa}$ and starting material (7 or 9). The respective rate constants (at $22^{\circ} \mathrm{C}$ ) are quite similar: $0.96 \times 10^{-4} \mathrm{M}^{-1} \mathrm{~s}^{-1}(7 \rightarrow 9), 0.61 \times 10^{-4}$ $\mathrm{M}^{-1} \mathrm{~s}^{-1}(7 \rightarrow 8), 4.46 \times 10^{-4} \mathrm{M}^{-1} \mathrm{~s}^{-1}(\mathbf{9} \rightarrow 8)$. A reaction mechanism is proposed and discussed.

\section{REFERENCES}

1. (a) M. Gall, J. M. McCall, R. E. TenBrink, P. F. VonVoigtlander and J. S. Mohrland, J. Med. Chem., 1988, 31, 1816-1820; (b) V. K. S. Leung, T. Y. K. Chan and V. T. F. Yeung, Clin. Toxicol., 1999, 37, 513-514; (c) S. J. Benkovic, T. H. Barrows and P. R. Farina, J. Am. Chem. Soc., 1973, 95, 8414-8420; (d) A. J. Meyers and R. Hutchings, Heterocycles, 1996, 42, 475-478; (e) S. Vincent, C. Mioskowski and L. Lebeu, J. Org. Chem., 1999, 64, 991-997 and references cited therein.

2. V. G. Granik, Russ. Chem. Rev., 1983, 52, 377-393.

3. R. H. De Wolfe, in "The Chemistry of amidines and imidates", S. Patai (Ed.), J. Wiley \& Sons, LondonSydney-New York-Toronto, 1975, ch. 8, p. 349-384.

4. (a) C. L. Perrin and G. M. L. Arrhenius, J. Am. Chem. Soc., 1982, 104, 2839-2842; (b) J. D. Halliday and E. A. Symons, Can. J. Chem., 1978, 56, 1463-1469; (c) M. Ono and S. Tamura, Chem. Pharm. Bull., 1990, 38, 590596; (d) M. Ono, R. Todoriki, I. Araya and S. Tamura,
Chem. Pharm. Bull., 1990, 38, 1158-1164; (e) C. L. Perrin, Acc. Chem. Res., 2002, 35, 28-34.

5. (a) C. Flinn, R. A. Poirier and W. A. Sokalski, J. Phys. Chem. A, 2003, 107, 11174-11181; (b) Y. Wu, L. Jin, Y. Xue, D. Q. Xie, C. K. Kim, Y. Guo and G. S. Yan, J. Comput. Chem., 2008, 29, 1222-1232; (c) J. Y. Gao, Y. Zeng, C. H. Zhang and Y. Xue, J. Phys. Chem. A, 2009, 113, 325-331; (d) Z. H. Cheng, X. Ying, G. Yong and Y. S. Guo, Chem. J. Chin. Univ., 2008, 29, 2354-2359.

6. (a) R. L. Shriner and F. W. Neumann, Chem. Rev., 1944, 35, 351-425; (b) M. Ono, I. Araya, R. Todoriki and S. Tamura, Chem. Pharm. Bull., 1990, 38, 1824-1831; (c) P. L. Anelli, M. Brocchetta, D. Palano and M. Visigalli, Tetrahedron Lett., 1997, 38, 2367-2368.

7. (a) H. W. Woodburn and L. N. Pino, J. Org. Chem., 1951, 16, 1389-1394; (b) H. M. Woodburn, B. A. Morehead and W. Bonner, J. Org. Chem., 1949, 14, 555558.

8. C. Florea, C. Stavarache and H. Petride, Rev. Roum. Chim., 2016, 61, 319-325.

9. F. C. Schaeffer and G. A. Peters, J. Org. Chem., 1961, 26, 412-418.

10. A. A. Frost and R. G. Pearson, "Kinetics and Mechanism", Wiley, 1956, p. 153-154.

11. H. Margenau and G. M. Murphy, "The Mathematics of Physics and Chemistry", D. Van Nostrand Co., Inc., Princeton-Toronto-London, $2^{\text {nd }}$ edition, 1956, p. 41-42.

12. Y. L. Wang, H. D. Lee, W. Beach and D. W. Margerun, Inorg. Chem., 1987, 26, 2444-2449. 
